\title{
Oral health status and its determinants among opiate dependents: a cross- sectional study
}

\author{
Hajar Shekarchizadeh ${ }^{1 *}$ (D) Mohammad R. Khami ${ }^{2,3}$, Simin Z. Mohebbi ${ }^{2,3}$, Hamed Ekhtiari ${ }^{4}$ and Jorma I. Virtanen ${ }^{5,6}$
}

\begin{abstract}
Background: In addition to numerous general health problems, drug dependents manifest various oral health disorders. Our aim was to investigate the oral health status and its determinants among in-treatment opiate dependents.

Methods: As part of a comprehensive cross-sectional survey on opiate dependents admitted to methadone maintenance centers in Tehran, Iran, we conducted a clinical study in two centers from different socioeconomic areas. A trained dentist conducted face to face interviews and clinical oral examinations based on World Health Organization (WHO) criteria for Decayed, Missing, Filled Teeth (DMFT) index and Community Periodontal Index (CPI) on volunteer patients. Student's t-test, Mann-Whitney U, Kruskal Wallis, and Chi ${ }^{2}$ tests, in addition to linear and logistic regression models served for statistical analysis $(p<0.05)$.
\end{abstract}

Results: A total of 217 patients ( $98 \%$ men), with a mean age of 43.6 years (SD 12.3) participated in the study. Opium was the main drug of abuse reported by $70 \%$ of the participants followed by crystalline heroin (22\%). Of the participants, 24.4\% were totally edentulous. The mean DMFT score of participants was 20.3 (SD 7.8). Missing teeth comprised the main part of the index followed by decayed and filled teeth. Older patients $(p<0.001)$ and the patients with a lower socioeconomic status $(p=0.01)$ had higher DMFT scores. None of the dentate patients had a healthy periodontium. Maximum CPI mostly consisted of shallow pockets (66\%) followed by calculus in 15\%, deep pockets in 11\%, and bleeding in $8 \%$ of the participants. Older participants $(p=0.02)$ and those who started drug abuse at a younger age $(p=0.01)$ were more likely to develop periodontal pockets.

Conclusions: Opiate dependents had a poor oral health status in terms of the dentition status and periodontal health. Missing teeth comprised the main part of their dental caries history and none had a healthy periodontium. Oral health care should be integrated into the package of general health services available in treatment centers.

Keywords: Dental caries, Opioid-related disorders, Oral health, Periodontal index, Substance-related disorders

\section{Background}

Although illicit drug abuse is not as prevalent as cigarette smoking, it can be considered a public health problem in many countries. The public health system bears a heavy burden from drug addiction for prevention and treatment of drug related consequences [1]. Based on the global burden of disease study, 12 million life years are lost due to early death or disability resulted from opioids, cocaine, amphetamines

\footnotetext{
* Correspondence: shekarchizadeh@razi.tums.ac.ir

'Department of Community Oral Health, School of Dentistry, Islamic Azad University, Isfahan (Khorasgan) Branch, University Blvd, Arqavanieh, Jey Street, P.O.Box: 81595-158, Isfahan, Iran

Full list of author information is available at the end of the article
}

and cannabis, of which about 8 million are linked to opioids [2]. The epidemic of opioids as a continental concern take places via drug trafficking, migration, and borders [3]. Opiates are the most potential harmful opioids with the highest consumption rate and seizures in Southwest Asia [2]. Moreover, North America has encountered the epidemic of opioid misuse, especially in the form of opioid analgesics, heroin, or both [3].

Drug addiction is a preventable condition which has various consequences at an individual level and on the wider society $[1,4]$. In addition to several general health problems, a growing number of evidence confirms the 
high prevalence of oral health problems in people with drug addiction, including generalized dental caries, periodontal disease, mucosal infection, candidosis, mucosal dysplasia, and bruxism [5-8]. These problems might result from the direct effect of drugs on oral health such as the acidic nature of the drugs, drug-induced bruxism, xerostomia, suppression of the immune system, appetite suppression, carving for sweet foods, and blocking the sense of pain. Moreover, they might be associated with drug dependents' life style factors, including poor nutrition, poor oral hygiene, and alcohol drinking and cigarette smoking in addition to other factors such as low use of dental services and self-medications [8-11].

Health care systems in different countries offer various services for people with drug addiction, including treatment services (medical detoxification, abstinence-oriented treatment, or substitution maintenance therapy), and prevention and harm-reduction facilities (needle-exchange programs, supervised injection facilities, naloxone distribution, and outreach services) [12-14]. Most systems, however, lack comprehensive oral care facilities for drug dependents. Implementation of oral health programs for these patients is challenging due to e.g. addicts' low priority on their oral health and compliance problems with their treatment plan [4].

Notably, a mutual association exists between addiction and oral health problems. Addiction can exacerbate oral complications on the one hand, and dental pain may result in relapse to drug abuse and reduced addiction treatment success rate on the other hand $[15,16]$. Thus, it is crucial to integrate dental care into general health services currently available for people with drug addiction [4]. For planning preventive and curative programs together with general health services for drug dependents, we aimed to investigate the oral health status and its determinants among people with opiate dependence admitted to methadone maintenance treatment.

\section{Methods}

\section{Subjects}

As part of a large cross-sectional survey of people with opiate dependence admitted to methadone maintenance treatment in Tehran, Iran in 2011 [17], we conducted a clinical study in two methadone maintenance programs located in two different socioeconomic areas of the city (north and south). In each center, all patients who met the DSM IV criteria for opioid dependence [18] were asked to participate. Data collection was continued to represent the monthly turnover as most of the patients have monthly visits. This ended to a total of 217 patients.

\section{Structured interviews about patients' demographics and drug abuse profile}

A trained dental clinician conducted 10-min face-to-face interviews to collect the patients' demographic characteristics and drug abuse profile. A standard form commonly applied in Iranian addiction studies was used to collect information on the patients' drug abuse profile (main drug of abuse which made the patient seek treatment, age at the start of drug use, duration of opiate dependence, and duration of current methadone treatment), in addition to their demographic characteristics (age, gender, educational level, marital status, occupational status, and residential area) [17]. As socioeconomic status (SES) indicators, educational level, marital status, occupational status, and residential area were dichotomized as follows: for education: higher education (high school diploma or higher) $=1$, lower education (less than high school diploma) $=0$; for marital status: married $=1$, single (single, widow, divorced) $=0$; for employment status: employed (full or part-time) $=1$, unemployed (unemployed, retired, housewife, and student $)=0$; and for residential area: affluent (north) $=1$, non-affluent $($ south $)=0$. The dichotomized scores were then summed up ranging from 0 to 4 [19].

\section{Oral examinations}

The same dental clinician, was trained and calibrated prior to the study. Training and calibration were based on written instructions, and on dental patients. Ten patients were examined and Intra-examiner reliability was more than 0.7. Clinical oral examinations were carried out under the artificial light of a mobile dental unit. DMFT (Decayed, Missing, and Filled Teeth) and CPI (Community Periodontal Index) using CPI probes and disposable dental mirrors were recorded according to the WHO criteria [20]. Criteria of decayed teeth were clinically visible lesions (cavity or undermined enamel), or when the explorer tip penetrated to the soft structures. No tooth cleaning was undertaken before the examination.

\section{Statistical analysis}

Statistical Package for the Social Science (SPSS for Windows, version 16.0/PC; SPSS, Chicago, IL, USA) was used for data analysis. Mean DMFT and corresponded Standard Deviation (SD) were calculated. Student's t-test, Mann-Whitney U, Kruskal Wallis, and $\mathrm{Chi}^{2}$ tests were employed for statistical analysis (level of significance <0.05). Linear and logistic regression models were fitted to the data to analyze the factors associated with drug dependents' DMFT and periodontal disease, respectively. 


\section{Results}

\section{Demographics and drug abuse profile}

As high as $98 \%$ of the participants were men (only 5 women). The mean age of the patients was 43.6 years (SD 12.3, rang 21-79). Table 1 presents the demographic characteristics of in-treatment opiate dependents. The majority of the patients had more than primary school education (87\%), were married (73\%), and were employed (68\%).

Opium was the main drug of abuse reported by $70 \%$ of drug dependents followed by crystalline heroin (22\%). The mean age of opium dependents ( $47 \mathrm{yrs}$ ) was higher than that of crystalline heroin users (35 yrs $)((p<0.001)$. The mean age at the start of drug use was 25.2 years (SD 8.8; range 11-67), and the mean duration of opiate dependence was 12.1 years (SD 8.6). The mean duration of current methadone treatment was 10.0 months (SD 15.3) (Table 2).

Table 1 Demographic characteristics of opiate dependents in methadone maintenance treatment $(n=217)$

\begin{tabular}{|c|c|c|}
\hline Variable & Number & Percentage \\
\hline \multicolumn{3}{|l|}{ Gender (n, \%) } \\
\hline Male & 212 & 98 \\
\hline Female & 5 & 2 \\
\hline \multicolumn{3}{|l|}{ Age $(n, \%)$} \\
\hline $18-24$ & 9 & 4 \\
\hline $25-34$ & 48 & 22 \\
\hline $35-44$ & 62 & 29 \\
\hline $45-54$ & 50 & 23 \\
\hline $55-64$ & 39 & 18 \\
\hline $65 \leq$ & 9 & 4 \\
\hline \multicolumn{3}{|c|}{ Educational status (n, \%) } \\
\hline Illiterate & 7 & 3 \\
\hline Elementary school & 21 & 10 \\
\hline High school & 145 & 67 \\
\hline University & 43 & 20 \\
\hline \multicolumn{3}{|l|}{ Marital status (n, \%) } \\
\hline Married & 158 & 73 \\
\hline Single & 35 & 16 \\
\hline Widow & 4 & 2 \\
\hline Divorced & 20 & 9 \\
\hline \multicolumn{3}{|c|}{ Employment status ( $n, \%)$} \\
\hline Full time job & 104 & 48 \\
\hline Part time job & 44 & 20 \\
\hline Unemployed & 32 & 15 \\
\hline Student & 1 & 0.5 \\
\hline Retired & 30 & 14 \\
\hline Housewife & 5 & 2 \\
\hline
\end{tabular}

Table 2 Drug abuse profile of opiate dependents in methadone maintenance treatment $(n=217)$

\begin{tabular}{lcl}
\hline Variable & Number & Percentage \\
\hline Main drug of abuse & 152 & 70 \\
Opium & 48 & 22.1 \\
Crystalline heroin & 17 & 7.8 \\
Other drugs & \\
Age at start of drug abuse & 31 & 14.4 \\
$\leq 17$ & 84 & 38.9 \\
$18-24$ & 71 & 32.9 \\
$25-34$ & 30 & 13.9 \\
$35 \leq$ & 5 & \\
Duration of opiate dependence (year) & 2.3 \\
$<1$ & 53 & 24.8 \\
$1-5$ & 62 & 29.0 \\
$6-10$ & 94 & 43.9 \\
$11 \leq$ & 24 & \\
Duration of current methadone treatment (month) & 13.9 \\
$<1$ & 30 & 38.9 \\
$1-5.9$ & 84 & 23.1 \\
$6-11.9$ & 50 & 11.1 \\
$12-23.9$ & 28 & 13.0 \\
$24 \leq$ & & \\
\hline
\end{tabular}

Oral health status

About one quarter $(24.4 \%)$ of the participants $(n=53)$ were totally edentulous. The mean DMFT of opiate dependents was 20.3 (SD 7.8; range 0-28). Missing teeth comprised the main part of the index (mean 13.6; SD 10.3; range 0-28) followed by DT (mean 4.8; SD 4.8; range 0-20) and FT (mean 1.8; SD 3.1; range 0-16). Table 3 presents the mean DMFT of the participants according to their background characteristics and drug abuse profile. In univariate analysis, a higher DMFT score was associated with older age $(p<0.001)$. Single participants and those who were employed showed lower DMFT scores $(p<0.001)$. The mean DMFT of opium dependents (21.7; SD 6.9) was higher than that of crystalline heroin dependents (16; SD 8.3) $(p<0.001)$. Patients who started drug use at an older age and those who had a longer history of drug dependence showed higher scores of DMFT $(p<0.001)$.

In multivariate analysis, older drug dependents $(p<$ $0.001)$ and patients with a lower socioeconomic status $(p=0.01)$ had higher scores of DMFT (Table 4).

Among dentate participants, the mean DMFT was 17.8 (SD 7.4), which mostly consisted of missing teeth (mean 9.0; SD 7.2). The mean DT and FT was 6.4 (SD 4.6) and 2.4 (SD 3.4), respectively. Similar results were found in multivariate analysis of factors 
Table 3 DMFT scores of in-treatment opiate dependents according to their backgrounds and drug abuse profile $(n=217)$

\begin{tabular}{|c|c|c|}
\hline Variable & DMFT (Mean, SD) & $p$-value \\
\hline \multicolumn{3}{|l|}{ Gender } \\
\hline Male & $20.3(7.7)$ & \multirow[t]{2}{*}{$0.852^{*}$} \\
\hline Female & $18.4(11.5)$ & \\
\hline \multicolumn{3}{|l|}{ Age } \\
\hline $18-24$ & $8.2(4.9)$ & \multirow[t]{5}{*}{$<0.001^{* *}$} \\
\hline $25-34$ & $14.6(7.9)$ & \\
\hline $35-44$ & $20.1(6.5)$ & \\
\hline $45-54$ & $22.5(6.0)$ & \\
\hline $55 \leq$ & $26.2(4.2)$ & \\
\hline \multicolumn{3}{|l|}{ Education } \\
\hline $0-5$ & $22.2(7.5)$ & \multirow[t]{3}{*}{$0.302^{* *}$} \\
\hline $6-12$ & $20.1(7.7)$ & \\
\hline $13 \leq$ & $19.4(8.3)$ & \\
\hline \multicolumn{3}{|l|}{ Marital status } \\
\hline Married & $21.1(7.2)$ & \multirow[t]{3}{*}{$0.001^{* *}$} \\
\hline Single & $15.3(9.0)$ & \\
\hline Others & $22.1(7.2)$ & \\
\hline \multicolumn{3}{|l|}{ Employment status } \\
\hline Full-time job & $18.5(7.8)$ & \multirow[t]{4}{*}{$<0.001^{* *}$} \\
\hline Part-time job & $18.8(8.3)$ & \\
\hline Unemployed & $22.7(6.2)$ & \\
\hline Others (student, retired, homemaker) & $24.9(6.6)$ & \\
\hline \multicolumn{3}{|l|}{ Area of residence } \\
\hline Affluent & $20.1(7.8)$ & \multirow[t]{2}{*}{$0.594^{*}$} \\
\hline Non-affluent & $20.8(7.9)$ & \\
\hline \multicolumn{3}{|l|}{ Main drug of abuse } \\
\hline Opium & $21.7(6.9)$ & \multirow[t]{3}{*}{$<0.001^{* *}$} \\
\hline Crystalline heroin & $16.0(8.3)$ & \\
\hline Other drugs & $19.2(9.7)$ & \\
\hline \multicolumn{3}{|l|}{ Age at start of drug abuse } \\
\hline$\leq 17$ & $14.7(8.3)$ & \multirow[t]{4}{*}{$<0.001^{* *}$} \\
\hline $18-24$ & $19.8(7.7)$ & \\
\hline $25-34$ & $21.4(7.1)$ & \\
\hline $35 \leq$ & $24.3(5.7)$ & \\
\hline \multicolumn{3}{|l|}{ Duration of opiate dependence (year) } \\
\hline$<1$ & $11.4(11.2)$ & \multirow[t]{4}{*}{$<.001^{* *}$} \\
\hline $1-5$ & $17.2(8.0)$ & \\
\hline $6-10$ & $19.4(7.6)$ & \\
\hline $11 \leq$ & $23.1(6.4)$ & \\
\hline \multicolumn{3}{|c|}{ Duration of current methadone treatment (month) } \\
\hline$<1$ & $19.7(7.4)$ & \multirow[t]{5}{*}{$0.870^{* *}$} \\
\hline $1-5.9$ & $19.5(8.9)$ & \\
\hline $6-11.9$ & $20.7(6.8)$ & \\
\hline $12-23.9$ & $21.6(5.0)$ & \\
\hline $24 \leq$ & $20.9(8.4)$ & \\
\hline
\end{tabular}

* Mann-Whitney $\mathrm{U},{ }^{*}$ Kruskal Wallis Test associated with DMFT among dentate opiate dependents (Table 4).

None of the dentate patients had a healthy periodontium. Max CPI mostly consisted of shallow pockets (66\%) followed by calculus (15\%), deep pockets (11\%), and bleeding (8\%). In univariate analysis, periodontal disease (pocket formation) was associated with none of the background or drug abuse variables $(p>0.05)$. Table 5 reveals factors associated with pocket formation among dentate opiate dependents. Older participants $(p=0.02)$ and those who started drug abuse at a younger age $(p=0.01)$ were more likely to develop periodontal pockets.

\section{Discussion}

The present study of oral health and its determinants among opiate dependents revealed poor oral health in terms of dentition and periodontal health. Missing teeth comprised the main part of their dental caries history and none of them had a healthy periodontium. Older drug users and patients of lower socioeconomic status were at greater risk of developing oral problems.

\section{Drugs and health / health behavior / oral health}

Patients with drug addiction show numerous health consequences, including heart attack, respiratory depression, liver cirrhosis, nephropathy, and infectious diseases such as hepatitis, AIDS, and tuberculosis [4]. In addition, mental disorders such as depression, injury-associated disabilities, and oral health problems are common in drug dependents [4].

In addition to the direct effects of drugs on the oral health, unhealthy behaviors are common in drug dependents. General personal neglect and poor dental hygiene, irregular eating pattern, high intake of carbohydrates, tobacco and alcohol dependence, low dental attendance, and low priority for oral health are lifestyle factors contributing to their oral health problems $[4,21]$.

\section{Dental caries experience}

The mean DMFT of the patients was 20.3 which mostly consisted of missing teeth (mean 13.6). The mean DMFT of opiate dependents in our study was about twice as high as the mean DMFT of the general middle-aged population in Tehran (mean: 11) [22]. However, MT comprises the main part of the index among both drug dependents and the general population. Compared to the general population (3\%) [22], about $16 \%$ of our study participants were totally edentulous. The highest DMFT score (26.2) was seen in the oldest age group $(55 \leq)$ while the youngest (18-24) had the lowest score (8.2) probably due to effect of age on dentition.

The DMFT of a group of in-treatment Spanish drug dependents was 22.7, excluding the four edentulous patients 
Table 4 Factors associated with DMFT of in-treatment opiate dependents as shown by a linear regression model

\begin{tabular}{|c|c|c|c|c|c|c|}
\hline \multirow[t]{2}{*}{ Varriable } & \multicolumn{3}{|c|}{ All patients $(210)^{c}$} & \multicolumn{3}{|c|}{ Dentate patients $(162)^{d}$} \\
\hline & Beta Coefficient & $P$-value & $95 \% \mathrm{Cl}$ & Beta Coefficient & $P$-value & $95 \% \mathrm{Cl}$ \\
\hline Age & 0.48 & $<0.001$ & $0.18-0.43$ & 0.49 & $<0.001$ & $0.24-0.43$ \\
\hline Socioeconomic status ${ }^{a}$ & -0.14 & 0.016 & $-1.98-(-0.21)$ & -0.16 & 0.016 & $-2.11-(-0.18)$ \\
\hline \multicolumn{7}{|l|}{ Main drug of abuse (Crystalline heroin) ${ }^{b}$} \\
\hline Opium & 0.12 & 0.077 & $-0.22-4.31$ & 0.07 & 0.383 & $-1.31-3.39$ \\
\hline Others & 0.04 & 0.514 & $-2.38-4.75$ & 0.04 & 0.567 & $-2.81-5.11$ \\
\hline Age at start of drug abuse & 0.01 & 0.912 & $-0.14-0.15$ & -0.07 & 0.470 & $-0.25-0.17$ \\
\hline Duration of opiate dependence (year) & 0.11 & 0.164 & $-0.04-0.24$ & 0.12 & 0.145 & $-0.04-0.28$ \\
\hline Duration of current methadone treatment (month) & 0.07 & 0.221 & $-0.02-0.09$ & 0.08 & 0.258 & $-0.04-0.15$ \\
\hline
\end{tabular}

${ }^{a}$ Combination of the following variables: area of residence, education, marital and employment status

${ }^{\mathrm{b}}$ Reference group

${ }^{c} R^{2}=0.40$

${ }^{d} R^{2}=0.25$

from analysis. Similar to our study, missing teeth comprised the main part of the index [5]. The mean DMFT of a group of drug dependents undergoing rehabilitation in Brazil (mean 14.9) [23], a group of remand prisoners in London (mean 14.2) [24], and a community of in-treatment alcohol and/or drug dependent persons from 3 outpatient public clinics in Brazil (13.0) [25] was lower than the mean DMFT in our study. The mean DMFT of a group of heroin users treated with methadone in a Chinese city [26] and a group of illicit drug dependents in a rehabilitation center in India [27] was 3.9 and 3.5 respectively, which is much lower than what we found. In both abovementioned studies, the prevalence of dental caries in their general populations was also lower than that of the Iranian general population [26, 27]. The lower DMFT score of the Chinese and Indian drug dependents might also be the result of the high percentage of people who were totally edentulous in our study, or might be due to the higher mean age of our participants (40.5 yrs) compared to the other two studies (about 35 yrs).

\section{Periodontal health status}

None of the patients in our study had a healthy periodontium. Similar results were found in Chinese heroin users $(0 \%)$ and Indian drug dependents $(2 \%)[26,27]$. In the present study $(66 \%)$ and in Indian drug dependents (44\%) [27], the max CPI index mostly consisted of shallow periodontal pockets. However, in the Chinese study, calculus comprised the main part of the index (66.3\%), followed by shallow periodontal pockets (27.6\%) [26].

Similar to our study, healthy periodontium was rare in middle aged general population of Tehran (1\%), and shallow periodontal pockets $(43 \%)$ and calculus (40\%) comprised the main parts of the index [22]. Based on another study in India, compared to the general population, drug dependents showed higher periodontal destruction and lower gingival bleeding [28]. Plaque and periodontal diseases were also prevalent among remand prisoners in London [24]. It seems that periodontal diseases are more prevalent among drug dependents in Iran than other countries

Table 5 Factors associated with periodontal disease (pocket formation) among dentate dependents by logistic regression model ( $n$ $=148)$

\begin{tabular}{|c|c|c|c|c|c|}
\hline Variable & ES & $\mathrm{SE}^{\mathrm{d}}$ & $P$-value & OR & $95 \% \mathrm{Cl}$ \\
\hline Age & 0.07 & 0.03 & 0.017 & 1.07 & $1.01-1.13$ \\
\hline Socioeconomic status ${ }^{\mathrm{b}}$ & 0.01 & 0.22 & 0.98 & 1.01 & $0.67-1.52$ \\
\hline \multicolumn{6}{|l|}{ Main drug of abuse (Crystalline heroin) ${ }^{c}$} \\
\hline Opium & -0.09 & 0.50 & 0.86 & 0.92 & $0.35-2.43$ \\
\hline Others & -0.10 & 0.74 & 0.89 & 0.90 & $0.21-3.82$ \\
\hline Age at start of drug abuse & -0.09 & 0.04 & 0.014 & 0.92 & $0.86-0.98$ \\
\hline Duration of opiate dependence & 0.02 & 0.05 & 0.65 & 1.02 & $0.93-1.11$ \\
\hline Duration of current methadone treatment (month) & -0.03 & 0.02 & 0.066 & 0.97 & $0.93-1.00$ \\
\hline
\end{tabular}

${ }^{\mathrm{a}}$ male $=0$, female $=1$

${ }^{\mathrm{b}}$ Combination of the following variables: area of residence, education, marital and employment status

${ }^{\mathrm{c}}$ Reference group

Goodness of fit with Hosmer and Lemeshow test $(p=0.66)$

${ }^{\mathrm{d}}$ Standard Error 
[26, 27]. The prevalence of periodontal diseases is high in both Iranian opiate dependents and the general population. However, the higher percentage of periodontal pockets as an indicator of periodontal destruction among drug dependents points out an urgent need to establish oral health promotion programs for people with drug addiction.

\section{Background and drug abuse profile}

In our study, the mean DMFT of opium dependents was higher than that of crystalline heroin dependents. This seems to be a result of the higher mean age of opium dependents than that of crystalline heroin users in our study (47 vs. 35 years respectively), which is consistent with other studies from Iran [17]. It is also commonly known that the DMFT index is higher among older age groups. Patients with a lower socioeconomic status showed higher DMFT scores. However, among Chinese former heroin users, DFT scores were related to sex and the duration of drug abuse after controlling the effect of education, occupation and age [26]. Among drug dependents in Australia, age, gender, and dose and/or duration of drug abuse were associated with dental destruction [29].

Regarding periodontal health, older dependents and those who started drug abuse at a younger age were more likely to develop periodontal pockets. Similar findings were reported in former drug dependents in China. Periodontal health was associated with duration of drug abuse and age of the participants [26]. Based on the study by Gupta et al. in India, drug abuse was independently related to a poor periodontal status [27].

\section{Limitations and strengths of the study}

Considering the scarcity of the data about oral problems among people with drug addiction, we managed portray oral health and its determinants in Iranian opiate dependents. However, no casual interpretation is possible due to the cross-sectional nature of the study. On the other hand, we studied opiate dependents attending maintenance treatment programs; thus, the results cannot be generalized to all drug dependents including prisoners and other street drug users. Objective data collection via clinical examination based on the WHO criteria and using a mobile dental unit provided valid information about participants' oral health status. In addition, the patients' demographics and drug abuse profile were collected via individual interviews instead of commonly applied self-administered questionnaires to increase the validity of the data. Recruiting patients from treatment centers in two main different socioeconomic areas of the city of Tehran is another strong point of the study.

\section{Conclusion}

The present study revealed a poor oral health status among opiate dependents in terms of their dentition status and periodontal health. Missing teeth comprised the main part of their dental caries history and none of them had a healthy periodontium. Older drug dependents and patients of lower socioeconomic status were at greater risk of developing dental problems. Thus, it is recommended to integrate oral health care into the package of general health services available in treatment centers. Educational, preventive, and treatment programs focusing on oral health should be targeted to these high risk patients in rehabilitation settings.

\section{Abbreviations \\ CPI: Community Periodontal Index; DMFT: Decayed, Missing, Filled Teeth; SD: Standard Deviation; WHO: World Health Organization}

\section{Acknowledgements}

Not applicable.

\section{Funding}

Data collection was funded by Tehran University of Medical Sciences and Health Services Grant number 12900.

\section{Availability of data and materials}

The datasets used and/or analysed during the current study are available from the corresponding author on reasonable request.

\section{Authors' contributions}

Conceived and designed the study: HS, MRK, SZM, HE, JIV. Collected data: HS. Analyzed the data: HS, MRK, and JV. Prepared the manuscript: HS, MRK, JIV. Critically revised the manuscript: SZM, HE. All authors read and approved the final manuscript.

Ethics approval and consent to participate

The study was voluntary and all respondents provided their written informed consent. Anonymous patient-characteristic forms and anonymous questionnaires were used for data collection. The Tehran University of Medical Sciences Ethics Committee approved the study (nr 90-01-69-12,900-1).

Consent for publication

Not applicable.

\section{Competing interests}

The authors declare that they have no competing interests.

\section{Publisher's Note}

Springer Nature remains neutral with regard to jurisdictional claims in published maps and institutional affiliations.

\section{Author details}

${ }^{1}$ Department of Community Oral Health, School of Dentistry, Islamic Azad University, Isfahan (Khorasgan) Branch, University Blvd, Arqavanieh, Jey Street, P.O.Box: 81595-158, Isfahan, Iran. ${ }^{2}$ Research Center for Caries Prevention, Dentistry Research Institute, Tehran University of Medical Sciences, Tehran Postal code 1417614411, Iran. ${ }^{3}$ Community Oral Health Department, School of Dentistry, Tehran University of Medical Sciences, Tehran Postal code 1439955934, Iran. ${ }^{4}$ Neurocognitive Laboratory, Iranian National Center for Addiction Studies, Tehran University of Medical Sciences, Tehran Postal code 1336616357, Iran. ${ }^{5}$ Department of Clinical Dentistry, University of Bergen, N-5020 Bergen, Norway. ${ }^{6}$ Medical Research Center, Oulu University Hospital, Fl-90029 Oulu, Finland. 
Received: 26 May 2018 Accepted: 10 December 2018

Published online: 07 January 2019

\section{References}

1. United Nations Office on Drugs and Crime. World drug report 2015. Vienna: United Nations publication; 2015

2. United Nations Office on Drugs and Crime. World drug report 2016. Vienna: United Nations publication; 2016.

3. Vashishtha D, Mittal ML, Werb D. The north American opioid epidemic: current challenges and a call for treatment as prevention. Harm Reduct J. 2017;14:7

4. Shekarchizadeh H, Khami MR, Mohebbi SZ, Ekhtiari H, Virtanen Jl. Oral health of drug abusers: a review of health effects and care. Iranian J Publ Health. 2013:42:929-40.

5. Mateos-Moreno MV, Del-Río-Highsmith J, Riobóo-García R, Solá-Ruiz MF, Celemín-Viñuela A. dental profile of a community of recovering drug addicts: biomedical aspects. Retrospective cohort study. Med Oral Patol Oral Cir Bucal. 2013;18:e671-9.

6. Hamamoto DT, Rhodus NL. Methamphetamine abuse and dentistry. Oral Dis. 2009:15:27-37.

7. Versteeg PA, Slot DE, van der Velden U, van der Weijden GA. Effect of cannabis usage on the oral environment: a review. Int J Dent Hyg. 2008;6:315-20.

8. Titsas A, Ferguson MM. Impact of opioid use on dentistry. Aust Dent J. 2002:47:94-8.

9. Brondani M, Park PE. Methadone and oral health--a brief review. J Dent Hyg. 2011:85:92-8.

10. Nathwani NS, Gallagher JE. Methadone: dental risks and preventive action. Dent Update. 2008:35:542-4 547-8.

11. Cretzmeyer M, Walker J, Hall JA, Arndt S. Methamphetamine use and dental disease: results of a pilot study. J Dent Child (Chic). 2007:74:85-92.

12. World Health Organization. Management of substance abuse. Country profiles: Resources for the prevention and treatment of substance use disorders. http://www.who.int/substance_abuse/publications/atlas_report/ profiles/en/index.htm/\#U. Accessed 17 May 2017.

13. World Health Organization. Assessment of compulsory treatment of people who use drugs in Cambodia, China, Malaysia and Viet Nam: An application of selected human rights principles; 2009. http://www.wpro.who.int/ publications/docs/FINALforWeb_Mar17_Compulsory_Treatment.pdf. Accessed 17 May 2017

14. Department of Health (England) and the devolved administrations. Drug misuse and dependence: UK quidelines on clinical management. London: Department of Health (England), the Scottish government, welsh assembly government and Northern Ireland Executive; 2007.

15. Madinier I, Harrosch J, Dugourd M, Giraud-Morin C, Fosse T. The buccaldental health of drug addicts treated in the university hospital Centre in Nice. Presse Med. 2003;32:919-23

16. Metsch LR, Crandall L, Wohler-Torres B, Miles CC, Chitwood DD, McCoy CB. Met and unmet need for dental services among active drug users in Miami. Florida J Behav Health Serv Res. 2002;29:176-88.

17. Shekarchizadeh $\mathrm{H}$, Ekhtiari H, Khami MR, Virtanen Jl. Patterns of pretreatment drug abuse, drug treatment history and characteristics of addicts in methadone maintenance treatment in Iran. Harm Reduct J. 2012:9:18.

18. American Psychiatric Association. Diagnostic and statistical manual of mental disorders. 4th ed. Text Revision. Washington, DC: American Psychiatric Association; 2000 .

19. Shekarchizadeh $H$, Khami MR, Mohebbi SZ, Virtanen I. Oral health behavior of drug addicts in withdrawal treatment. BMC Oral Health. 2013;13:11.

20. World Health Organization. Oral health surveys: basic methods. 5th ed. Geneva: World Health Organization; 2013.

21. Robinson PG, Acquah S, Gibson B. Drug users: oral health-related attitudes and behaviours. Br Dent J. 2005;198:219-24.

22. Hessari H, Vehkalahti MM, Eghbal MJ, Murtomaa HT. Oral health among 35to 44-year-old Iranians. Med Princ Pract. 2007:16:280-5.

23. Ribeiro Edel P, Oliveira JA, Zambolin AP, Lauris JR, Tomita NE. Integrated approach to the oral health of drug-addicted undergoing rehabilitation. Pesqui Odontol Bras. 2002;16:239-45.

24. Heidari E, Dickinson C, Wilson R, Fiske J. Oral health of remand prisoners in HMP Brixton. London Br Dent J. 2007;202:E1

25. Marques TC, Sarracini KL, Cortellazzi KL, Mialhe FL, de Castro Meneghim M, Pereira AC, Ambrosano GM. The impact of oral health conditions, socioeconomic status and use of specific substances on quality of life of addicted persons. BMC Oral Health. 2015:15:38.

26. Ma H, Shi XC, Hu DY, Li X. The poor oral health status of former heroin users treated with methadone in a Chinese city. Med Sci Monit. 2012;18:PH51-5.

27. Gupta T, Shah N, Mathur VP, Dhawan A. Oral health status of a group of illicit drug users in Delhi. India Community Dent Health. 2012;29:49-54.

28. Reddy S, Kaul S, Agrawal C, Prasad MG, Agnihotri J, Bhowmik N, Amudha D, Kambali S. Periodontal status amongst substance abusers in Indian population. ISRN Dent. 2012:2012:460856.

29. Reece AS. Dentition of addiction in Queensland: poor dental status and major contributing drugs. Aust Dent J. 2007:52:144-9.

\section{Ready to submit your research? Choose BMC and benefit from:}

- fast, convenient online submission

- thorough peer review by experienced researchers in your field

- rapid publication on acceptance

- support for research data, including large and complex data types

- gold Open Access which fosters wider collaboration and increased citations

- maximum visibility for your research: over $100 \mathrm{M}$ website views per year

At BMC, research is always in progress.

Learn more biomedcentral.com/submissions 